\title{
Educação e arquitetura na era digital: um estudo sobre a expansão das instituições federais de ensino superior em Barreiras, Bahia
}

\author{
Education and architecture in the digital age: a study on the expansion of federal \\ institutions of higher education in Barreiras, Bahia
}

\author{
Nelson De Luca Pretto* \\ Helena Avanzo ${ }^{* *}$
}

\section{Resumo}

Este artigo tem o objetivo de discutir a expansão do ensino superior no Brasil no contexto da cultura digital contemporânea, com o foco na relação entre educação e arquitetura. Após análise deste contexto e de um panorama sobre as políticas públicas recentes, visando à expansão da universidade brasileira, discutimos os desafios que a cultura digital traz para a educação contemporânea e seus reflexos na arquitetura. Nesta análise, consideramos a arquitetura como um elemento de um currículo que denominamos de (in)visível. Com dados de uma pesquisa de campo sobre a expansão de duas instituições de ensino superior na Bahia, a Universidade Federal do Oeste da Bahia (Ufob) e o Instituto Federal de Educação, Ciência e Tecnologia - Bahia (Ifba), ambos na cidade de Barreiras, desenvolvemos, ao final, a ideia de que outras arquiteturas são necessárias para as edificações do ensino superior no contexto contemporâneo, imerso em tecnologias digitais de informação e comunicação.

Palavras-chave: Arquitetura. Cultura digital. Ensino superior.

\section{Abstract}

This article discuss the expansion of higher education in Brazil in the context of contemporary digital culture, focusing on the relationship between education and architecture. After analysis of this context and with an overview of recent public polices, whose goals have been the expansion of public university system in the country, we discuss the challenges that digital culture brings to contemporary education and its impact on the architecture of places for learning. We consider the architecture to be an element of the curriculum, which we call the (in)visible curriculum. We examine two higher education institutions in Bahia State, the Federal University of the West of Bahia (Ufob) and the Federal Institute of Education, Science and Technology - Bahia (Ifba), both in the town of Barreiras. We note that alternative/innovative architectures for university buildings are required in the contemporary context of which digital information and communication technologies are an integral part.

Keywords: Architecture. Digital culture. Higher education.

Recebido em 13/07/2017 - Aprovado em 22/12/2017

http://dx.doi.org/10.5335/rep.v25i1.8039

Doutor em Ciências da Comunicação pela Universidade de São Paulo (1994). Professor Associado III da Faculdade de Educação da Universidade Federal da Bahia. Pesquisador do Conselho Nacional de Desenvolvimento Científico e Tecnológico. E-mail: nelson@pretto.pro.br

** Mestre em Educação pela Faculdade de Educação da Universidade Federal da Bahia (2015). Docente EBTT do Instituto Federal de Educação, Ciência e Tecnologia da Bahia. E-mail: havanzo@yahoo.com 


\section{0 contexto: cultura digital e expansão do ensino superior}

A sociedade contemporânea tem como uma de suas características mais fundamentais o uso intensivo das tecnologias digitais de informação e comunicação em rede, que vem provocando profundas alterações na relação entre os sujeitos, impulsionando e transformando os mecanismos de produção e circulação de informações e conhecimentos. A tecnologia digital permite o acesso a um maior número de informações, além de possibilitar também alterar a informação recebida, colaborando e remixando, enfim, produzindo novos conhecimentos.

Essa possibilidade de intervir, de interação entre sujeitos e informação, altera a relação desses com o conhecimento, passando de uma lógica centrada no consumo para a de produção, o que, segundo André Lemos (2004), permite a qualquer indivíduo - potencialmente, é bom que se afirme - emitir e receber informação, em tempo real, de qualquer lugar do planeta, alterando e adicionando informações e instituindo um importante processo de colaboração.

A possibilidade de emissão de informação, em tempo real e de qualquer lugar, inicia-se com a popularização da internet, na década de 1990, e avança velozmente a partir do desenvolvimento da computação sem fio e da miniaturização dos equipamentos. Nesse contexto, as redes, antes definidas por fatores geopolíticos e limites físicos, passam a se configurar pela interação dos sujeitos, de forma independente do tempo e do espaço. A conectividade, que nos permite estar ligados em rede e em qualquer lugar, é, segundo Manuel Castells (1999), a característica que define a chamada sociedade em rede, ou, para Lemos (2002), a era da conexão.

Essa sociedade em rede e conectada produz a cibercultura, que é definida por Pierre Lévy como: "o conjunto de técnicas (materiais e intelectuais) de práticas, de atitudes, de modos de pensamento e de valores que se desenvolvem juntamente com o crescimento do ciberespaço" (1999, p. 17). Assim, diante dessa ampliação do espaço e em busca de entender um pouco mais sobre esse processo de mudanças na sociedade, tornam-se necessários estudos sob uma nova perspectiva, de ser e estar nesse mundo. Diante disso, neste artigo, trazemos esta discussão para o campo da relação entre educação superior e arquitetura na contemporaneidade.

Para fundamentar esse estudo, é necessário considerar que a rede federal de ensino superior passa, desde 2007, por um processo de expansão, inserido no Plano de Desenvolvimento da Educação (PDE) (BRASIL, 2007) e centrado, no caso das instituições de ensino superior (IES) públicas, no Programa de Apoio a Planos de Reestruturação e Expansão das Universidades Federais (Reuni) (BRASIL, 2007). ${ }^{1}$ Nesse contexto, novas instituições foram construídas e outras, já existentes, foram ampliadas. A pesquisa que deu origem a este texto analisou essa política de expan- 
são tomando como base duas instituições públicas no interior da Bahia: o Instituto Federal de Educação, Ciência e Tecnologia - Bahia (Ifba - Barreiras) e a Universidade Federal do Oeste da Bahia (Ufba - Barreiras, hoje Ufob) (AVANZO, 2015).

Segundo Dermeval Saviani (2007), o PDE, que foi lançado em 2007 (BRASIL, 2007), configurou-se como um grande guarda-chuva para abrigar praticamente todos os programas em desenvolvimento pelo Ministério da Educação (MEC). Para a educação tecnológica e a formação profissional, as ações garantiram a reorganização das escolas técnicas e profissionais em uma rede de Institutos Federais de Educação, Ciência e Tecnologia (IFs), a ampliação do número de unidades, a restruturação das unidades existentes e o concurso para contratação de professores (SAVIANI, 2007). Essa reorganização faz com que os IFs sejam considerados como instituições que se assemelham à universidade, com cursos de graduação e pós-graduação, além dos já tradicionais cursos técnicos, subsequentes e médios integrados.

Segundo Maria Estela Franco et al. (2010), o Reuni teve como objetivo a ampliação do acesso ao ensino superior, com a proposta de melhor aproveitamento da estrutura física por meio do aumento do número de alunos por professor, da implantação e da ampliação da oferta de cursos noturnos, da contratação de mais professores e servidores técnico-administrativos e técnico-artísticos e de uma anunciada preocupação com a elevação da qualidade do ensino ofertado, com base na revisão da estrutura acadêmica, na reorganização dos cursos de graduação e na atualização de metodologias de ensino e aprendizagem. ${ }^{2}$ A proposta original, de 2007, pretendia dobrar o número de vagas ofertadas pelas universidades federais, em um período de dez anos, e, para isso, além de cursos noturnos, diversos campi foram abertos, ou ainda estão previstos, a fim de levar a educação superior pública para o interior do país.

O MEC apresenta, no seu portal na internet, o quadro dessa expansão, indicando a ampliação da rede federal de ensino entre 2004 e 2014. Em todo o Brasil, o número de universidades subiu para 63, com o acréscimo das 18 novas universidades, e o número de campi passou de 148, em 2002, para 321, em 2014. Na Bahia, foram criadas a Universidade do Oeste da Bahia (Ufob), a Universidade Federal do Recôncavo (UFRB) e a Universidade Federal do Sul da Bahia (Ufesb), além de um campus da Universidade da Integração Internacional da Lusofonia Afro-Brasileira (Unilab) (Campus dos Malês).

A Rede Federal de Educação Profissional e Tecnológica também passou por recente processo de expansão, com o investimento total de $\mathrm{R} \$ 4,1$ bilhões entre 2011 e 2013. O número de unidades em operação passou de 354, em 2010, para 527, em 2014. Ainda de acordo com o MEC, ${ }^{3}$ por meio do Painel Público, com a Expansão da 
Educação Superior, Profissional e Tecnológica, na Bahia, por exemplo, que contava com nove IFs em 2002, foram criadas mais 10 unidades entre 2003 e 2010 e mais 12 unidades entre 2010 e 2014.

Uma vez que os dados apresentados evidenciam a grande ampliação do número de instituições ou de campi, torna-se importante avaliar as concepções de educação e de arquitetura presentes nessa expansão, tomando como locus da pesquisa as duas instituições já referidas.

\section{A arquitetura como currículo (in)visível}

A arquitetura, embora não seja identificada de imediato como um fator determinante, interfere no dia a dia das atividades educativas. Essa interferência pode ser observada em questões mais básicas, como projetar um filme sem o devido controle da luminosidade externa, e em questões mais complexas, como a necessidade de reconfiguração da estrutura do espaço como um todo, com locais para desenvolver atividades de gravação e edição de vídeos ou a programação de computadores.

Nesse sentido, Cleide Almeida e Luis Octávio Rocha (2009), citando Luís Carlos Sales (2005), consideram que a arquitetura se configura como uma espécie de "currículo (in)visível", que tanto pode propiciar quanto dificultar os processos educativos, ou seja, embora a estrutura física seja visível, há nuanças na relação ambiente-sujeito que são definidas pela arquitetura e nos passam despercebidas.

Para estudar esse currículo (in)visível, é preciso considerar, inicialmente, que o termo currículo não se restringe à seleção de informações, saberes e culturas a ser transmitida aos alunos pelos professores. O currículo tem uma dimensão muito mais ampla, pois, como afirma Roberto Sidnei Macedo (2012), deve ser compreendido como um complexo cultural tecido por relações ideologicamente organizadas e orientadas, sendo, portanto, uma construção social. Na perspectiva teórica adotada pelo autor, é de fundamental importância "considerar a ação, a atividade humana simbolicamente mediada, como fundante para se compreender como as ordens sociais constituem-se a partir do seu contexto e do seu cotidiano" (MACEDO, 2013, p. 28 , grifos do autor). Pensando nos aspectos educacionais, de vertentes tecnicistas, que não considerem esses contextos e cotidianos apontados, o autor afirma:

Cursos e escolas orientados por módulos organizados por padrões de escolarização pré-prontos, por exemplo, estão indo cada vez numa direção de um poder simbólico nada digno em termos políticos e morais. A função do controle aí se esconde atrás de um prestígio nacional conquistado por poderosas jogadas editoriais econômicas (MACEDO, 2013, p. 29, grifo nosso). 
Em relação à arquitetura, os módulos das edificações padrão preconcebidas estão representando concepções educacionais e arquitetônicas similares, ou seja, uma arquitetura padronizada para uma educação padronizada. Nesse sentido, seguindo a definição de currículo como construção social e de arquitetura como currículo (in)visível, Antonio Viñao Frago e Augustín Escolano (2001) propõem que o espaço escolar seja investigado como uma construção cultural que expressa e reflete, para além da sua materialidade, determinados discursos. Para esses autores, "a arquitetura escolar é também, por si mesma, um programa, uma espécie de discurso que institui na sua materialidade um sistema de valores, como os de ordem, disciplina e vigilância" (2001, p. 26).

Portanto, considerando a arquitetura como "uma forma silenciosa de ensino", ainda segundo Frago e Escolano (2001), podemos entendê-la como uma linguagem, uma vez que, como afirma Solange Ribeiro (2004), o espaço não é neutro, sendo formado pelos símbolos e pelas marcas de quem o produz, organiza e nele convive, por isso mesmo tem significações afetivas e culturais, o que torna a arquitetura um elemento efetivo do currículo (in)visível.

Alguns aspectos ligados aos projetos arquitetônicos podem ser trazidos ao texto para um melhor entendimento das relações entre esses elementos da arquitetura e a educação.

Estudos na área de arquitetura desenvolvidos sobre instituições de ensino utilizam a Técnica de Avaliação Pós-Ocupação (APO), que busca identificar e compreender como os espaços interferem nas atividades do processo educativo (ORNSTEIN, 2005). Assim, embora não façam uma relação direta com o conceito de currículo (in)visível, esses estudos trabalham com um elemento inerente a essa concepção e que nos escapa: a linguagem da arquitetura.

Quando consideramos que há tal linguagem, temos por base o princípio de que a arquitetura comunica, pois transmite mensagens. Um edifício pode produzir múltiplas sensações, relacionadas não somente ao conforto ambiental, térmico ou lumínico, mas atreladas àquilo que a forma do ambiente nos proporciona. Há, nesse conceito de linguagem arquitetônica, uma relação entre arquitetura e psicologia, que considera, segundo Sheila Ornstein (2005), a relação entre o comportamento humano e o ambiente construído, o que se denomina de psicologia ambiental. É essa linguagem arquitetônica que conduz, inibe ou estimula, ou seja, interfere no comportamento e no sentimento dos sujeitos que vivenciam um espaço, e que, na educação, para nós, passa a ser tratada como currículo (in)visível.

No entanto, a construção de um ambiente não determina exclusivamente $o$ seu uso. Muitas vezes, a ocupação de um espaço dá-se de maneira distinta da que se tinha projetado para ele. Acrescente-se a isso que, no contexto da sociedade em 
rede, a utilização desses espaços ganha nova demanda: a conexão. Segundo Salete Cordeiro (2014), novas territorialidades surgem em função do uso das tecnologias móveis. Espaços antes não frequentados pelos alunos podem vir a ser ocupados quando oferecem sinal de conectividade com a internet. Logo, o uso dos espaços depende não somente do projeto arquitetônico, mas das condições para apropriação e utilização desses espaços.

Logo, no contexto atual, marcado pela dinâmica das tecnologias digitais e das redes, é preciso considerar a arquitetura um elemento do currículo (in)visível na construção do espaço de ensino-aprendizagem, para buscar compreender a relação entre a arquitetura e a educação.

\section{Os desafios trazidos pela cultura digital}

Na contemporaneidade, a educação está imersa na cultura digital, e já não nos é possível decidir se devemos ou não inserir essas tecnologias nas instituições de ensino, uma vez que elas adentram as escolas por diversos meios e caminhos. Elas já estão presentes, institucionalizadas ou não, e os desafios estão pautados pelo modo como a educação dialoga com as demandas da cultura digital.

A presença das tecnologias digitais e das redes nas instituições de ensino não deve ser considerada apenas como um simples processo de modernização das práticas educacionais instituídas, com vistas a um aumento na produção. Não consideramos também que elas cheguem às escolas na perspectiva de ilustrar ou animar as práticas pedagógicas já instituídas. As tecnologias trazem novos desafios às práticas pedagógicas, impondo-nos intensificar o debate sobre a concepção de educação na contemporaneidade, buscando compreender de que forma reconfiguram o desenho dos espaços (físicos e simbólicos) da educação.

Historicamente, as instituições de ensino trabalham no sentido da reprodução e da transmissão do modelo hegemônico de um conhecimento que deve ser ensinado ao estudante, com o professor sendo, se não o detentor, pelo menos, o portador e controlador do conhecimento, de uma espécie de "verdade" que deve ser ensinada. Uma experiência educacional com crianças, realizada na Faculdade de Educação da Ufba, em 1997, ${ }^{4}$ evidenciou a crença, por parte dos próprios estudantes, de que o que se aprende fora da sala de aula é visto com desconfiança e com reserva.

Com a presença das tecnologias digitais e da internet, a informação, que antes era de domínio do professor e dos materiais didáticos, notadamente os livros didáticos, agora está na rede, disponível aos alunos a qualquer momento. A informação, antes unirreferenciada na escola e na universidade, passa, agora, pelo menos potencialmente, a ser multirreferenciada. É importante, mais uma vez, relativizar 
essa afirmação, razão pela qual incluímos, desde as primeiras linhas deste artigo, o termo potencialmente, uma vez que não basta que ela - a informação - esteja disponível na rede, pois é preciso ter condição plena de acesso para encontrá-la, e, ao encontrá-la, é preciso realizar uma leitura crítica dessa informação. São, portanto, vários os desafios trazidos pela cultura digital à sociedade e à escola, em particular.

Mais um desafio, atrelado ao anterior, é considerar o verbo compartilhar como condição para que essa educação aconteça de forma coletiva, levando em consideração a dinâmica da rede, em que cada nó é potencialmente um produtor e um transmissor de informações e conhecimentos. Para isso, faz-se necessária uma conexão com a internet, em banda larga, que seja de qualidade e esteja disponível para toda e qualquer instituição de ensino o tempo todo.

Outro importante desafio é a redefinição do papel do professor e do estudante em sala de aula. Uma vez que as informações estão disponíveis nas redes, o professor deixa de ser o provedor das informações e passa a atuar como o coordenador de um amplo processo de construção de conhecimentos junto aos seus alunos. Estes, assim, deixam de ser consumidores de informação, para se tornarem produtores de informações, culturas e conhecimentos; para tal, é-lhes demandada uma participação ativa e efetiva em todo o processo de formação. Com isso, fica diluída a relação dicotômica do professor que ensina, transmite informações, e do aluno que apreende, capta, retém as informações.

O desafio seguinte é a formação de professores para o uso de todas as potencialidades que as tecnologias digitais e as redes apresentam, para que esse uso não se restrinja apenas ao caráter ferramental e possa ser entendido como um elemento fundante na construção do conhecimento. No entanto, apesar dessa transformação necessária, não é suficiente que existam professores comprometidos e qualificados, pois não podemos atribuir apenas a eles a responsabilidade pela mudança. Necessário se faz que sejam considerados igualmente importantes a gestão da educação, o currículo e os espaços arquitetônicos, como elementos imprescindíveis à efetivação desse processo. Assim, chegamos ao desafio foco da pesquisa, qual seja o de identificar as demandas da educação contemporânea para a definição dos espaços apropriados.

\section{A pesquisa com as instituições em Barreiras, Bahia}

A pesquisa qualitativa descritiva desenvolvida entre 2014 e 2015 analisou duas instituições de ensino superior na cidade de Barreiras, no oeste da Bahia: o Instituto Federal de Educação, Ciência e Tecnologia da Bahia (Ifba - Campus Barreiras), uma instituição com mais de vinte anos de construção, que, recentemente, 
passou por uma ampliação para atender às demandas de implantação de dois cursos de nível superior; e a Universidade Federal do Oeste da Bahia (Ufob - Campus Edgard Santos), no bairro Prainha, que teve toda sua estrutura construída especificamente para atender às demandas dessa universidade, criada em 2013.

A pesquisa considerou a percepção dos sujeitos envolvidos, sendo docentes, técnicos administrativos e discentes dessas instituições, considerados como demandantes, que participaram de grupos de conversas coletivas. Foram ouvidos também os projetistas, por meio de entrevistas individuais com a arquiteta e o engenheiro que participaram do desenvolvimento dos projetos arquitetônicos das instituições pesquisadas. Com base no contexto de expansão da rede federal de ensino superior, nos projetos arquitetônicos construídos e nas percepções dos sujeitos, o objetivo da pesquisa foi identificar como a arquitetura dessas recentes construções nessas instituições considerou as demandas da educação contemporânea diante dos desafios trazidos pela cultura digital.

Quanto aos demandantes e aos projetistas, a pesquisa revelou que eles não têm a percepção das demandas da educação superior diante dos desafios postos pela cultura digital, que refletiu na arquitetura construída das duas instituições. Em relação a essa arquitetura, o que se pode observar, no caso das duas instituições pesquisadas, é que os projetos arquitetônicos desenvolvidos foram realizados de maneira aligeirada, utilizando-se, portanto, projetos-padrão, que se repetiram, por exemplo, no caso baiano, nos diversos campi do Ifba e na Ufob sem uma prévia discussão das concepções de arquitetura e de educação inerentes ao contemporâneo.

Embora Anilson Gomes (2012) não tenha se referido à repetição de projetos arquitetônicos em seu livro sobre o Panorama da infraestrutura do Ifba, com base nas imagens das plantas arquitetônicas de situação dos campi, pudemos perceber que o projeto arquitetônico desenvolvido para o campus de Camaçari foi repetido para os de Feira de Santana, Seabra, Ilhéus, Jacobina, Jequié e Irecê. No entanto, trata-se de cidades com climas distintos; e, diante disso, pode-se incorrer em construções que não atendem às condições de conforto ambiental. ${ }^{5}$

$\mathrm{O}$ projeto arquitetônico da Ufob também foi o mesmo utilizado na UFRB, na Universidade Federal do Vale do São Francisco (Univasf) e no Instituto de Medicina e Saúde (IMS) de Vitória da Conquista. Dessa forma, constatamos que os projetos arquitetônicos desenvolvidos seguiram projetos-padrão já existentes, mantendo a configuração arquitetônica da educação instituída, priorizando salas de aula para atividades teóricas e laboratórios para aulas práticas complementares, mantendo o foco na figura do professor detentor do conhecimento. 
Em relação ao uso das tecnologias digitais e das redes, no Ifba, há grandes lacunas, pois há internet disponível apenas no setor administrativo, na sala dos professores e nos laboratórios de informática. Já a Ufob compartilha um link dedicado de $100 \mathrm{Mb}$ de internet e disponibiliza internet Wi-Fi para estudantes na biblioteca, e, se o professor solicitar, há internet por cabos na sala de aula. Embora essa estrutura seja considerada adequada pelos professores, os estudantes consideram que suas demandas não foram atendidas em razão de, nas salas de aula, os pontos de energia e de rede estarem locados apenas na posição em que o professor atua.

Diante dos resultados, percebemos que a arquitetura das instituições estudadas ainda está pautada no modelo instituído. Professores ainda se sentem pouco preparados para o uso das tecnologias digitais e das redes, enquanto os estudantes as utilizam mais como meio de comunicação e entretenimento do que na produção de conhecimento. Consideramos, então, que a educação, embora imersa no contexto digital atual, ainda não se apropriou das tecnologias digitais e das redes nos processos educativos, não havendo, ainda, uma percepção mais desenvolvida sobre as demandas da educação no contexto da cultura digital; diante disso, a arquitetura das instituições de ensino não consideram essas demandas.

\section{Construindo outras arquiteturas}

O crescente uso das Tecnologias de Informação e Comunicação (TICs), na educação presencial e a distância, vem demandando uma reconfiguração de seus espaços, que atenda às exigências da educação contemporânea, o que nos levou a buscar compreender a inadequação dos atuais modelos arquitetônicos das instituições de ensino analisadas. Ao aventar possibilidades de outras arquiteturas, mesmo apresentando apenas dois dos muitos exemplos que precisariam ser analisados, buscamos uma construção coletiva de elementos que contribuam para melhor pensarmos a relação entre arquitetura e educação. Assim fazemos, pois temos como inspiração as ideias trazidas pela cultura hacker, que preconiza o compartilhamento como um dos princípios que promovem a ampliação dos conceitos, em função da participação coletiva de todos os interessados. Dessa forma, buscamos, coletivamente, a construção de outras arquiteturas para o ensino superior brasileiro.

Outro olhar para a relação entre a arquitetura e a educação precisa considerar as tecnologias digitais e as redes como elementos fundantes da educação e dos seus espaços. Diante disso, a construção de outras arquiteturas para as instituições de ensino superior tem por base princípios como a interatividade, a mobilidade, a flexibilidade e a reciclagem, ou seja, uma arquitetura mais fluida, permitindo ao sujeito reconfigurações dos espaços, adaptando-os às suas demandas de forma 
quase que cotidiana. Assim, a construção arquitetônica deixa de ser estanque, finalizando-se na entrega do edifício aos futuros usuários, e passa a se configurar como um processo contínuo, uma construção colaborativa com os projetistas e os sujeitos, que, por sua vez, deixariam de ser apenas usuários dos espaços, mas conformadores desses ambientes.

Outro elemento importante a considerar é que o contemporâneo exige pensar a educação em uma perspectiva plural, ou seja, em educações (PRETTO; COSTA PINTO, 2006). Assim, a sala de aula, como espaço instituído para essas educações, também não deve ter um padrão único, pois é preciso conjugar as múltiplas linguagens da cultura digital a espaços multimidiáticos de produção de vídeo, televisão e rádio, espaços de experimentação, com hardwares (sempre pensamos nos livres!) e programação de computadores, ou seja, espaços outros, que possibilitem e estimulem a construção coletiva do conhecimento. Para Pretto,

[...] pensar a escola contemporânea, que será a preparadora dos jovens de hoje e do amanhã, implica em rearrumá-la arquitetonicamente, aproximando-se mais de experiências como a dos laboratórios hackers, fab $l a b s^{6}$ ou Pontos de Cultura, com a implantação de espaços multimidiáticos de produção de vídeo, televisão e rádio, de espaços para a produção textual nas diversas linguagens e com os diversos suportes, de espaços da experimentação com hardwares livres, como o Arduíno, que vem viabilizando a construção das revolucionárias impressoras 3D [...], com a implantação de programação de computadores para a meninada, desde a mais tenra idade, entre tantas outras ações a serem oferecidas à juventude (PRETTO, 2014, p. 8).

Não é recente a constatação de que a escola, em sua estrutura física, em sua configuração arquitetônica e na estrutura pedagógica, com seus currículos, componentes curriculares e materiais didáticos, já não atende aos novos desafios postos à educação na contemporaneidade, como apresentado por diversos autores, tanto na área da arquitetura, como Ester Buffa e Gilson Pinto (2009), quanto na área da educação, como Salete Cordeiro (2014), Ana Lúcia Amaral (2012), entre outros.

No entanto, entendemos que a arquitetura é uma produção em parceria, ou seja, uma construção projetada por sujeitos para atender a demandas de outros. Para que os projetos arquitetônicos considerem esse conjunto de demandas trazidas pela educação, ou educações, na era digital, é preciso, por um lado, que os demandantes dos projetos - a comunidade escolar, dentre os quais, direção, servidores técnico-administrativos e técnico-artísticos, professores e estudantes - tenham consciência de suas necessidades quanto ao uso dos ambientes. De outro lado, os profissionais envolvidos nos projetos, entre gestores, arquitetos e engenheiros, precisam considerar essas transformações que acompanham, mesmo que de forma ainda tímida, a educação e, com isso, evitar que, ao desenvolverem os projetos arquitetônicos, o façam a partir apenas de sua experiência individual ou de conhe- 
cimentos adquiridos em sua formação - o que, na verdade, se dá ainda nessa escola instituída -, e, com isso, continuem a projetar e a construir novas edificações, com base em um modelo instituído de educação, centrado na sala de aula e, no máximo, em laboratórios.

É preciso que se intensifique um diálogo que continua ausente, como afirma Ana Beatriz Faria (2012). Segundo a autora, falta uma interlocução entre os sujeitos das áreas de arquitetura e pedagogia, gerando, portanto, uma distância entre projetos e concepções, tanto de arquitetura como de educação. Quando, eventualmente, é mantida alguma comunicação, esta tem como base a questão da forma-função, sendo a arquitetura responsável pela "forma" e a pedagogia, pela "função". É necessária a integração entre essas duas áreas, considerando que: "Não se trata, pois, do que os arquitetos podem ou não 'fazer' pela Pedagogia: belas escolas, espaços lúdicos, criativos, etc. [...] É um caminho de mão dupla, onde arquiteturas se educam nas pedagogias e as pedagogias se especializam no projeto e nas suas arquiteturas [...]" (FARIA, 2012, p. 101).

Para isso, além do diálogo entre essas duas áreas, é imprescindível romper com as fronteiras do instituído e experimentar outras arquiteturas, capazes de considerar as demandas da educação no contexto da cultura digital. É preciso, simultaneamente, repensar a educação e a arquitetura, para que, nesse processo, possamos construir os espaços necessários para a educação dos dias de hoje, preparada para o amanhã.

\section{Notas}

1 Disponível em: <http://portal.mec.gov.br/expansao/>. Acesso em: 20 jan. 2015.

2 Segundo relatório do MEC, um dos objetivos do Reuni é: "III - Revisão da estrutura acadêmica, com reorganização dos cursos de graduação e atualização de metodologias de ensino-aprendizagem, buscando a constante elevação da qualidade" (BRASIL, 2012).

3 Disponível em: <http://portal.mec.gov.br/expansao/>. Acesso em: 15 fev. 2014.

4 Aula inaugural do semestre letivo da Faculdade de Educação com oito crianças e jovens levados a discutir o uso das TICs na suas vidas e na escola. Vídeo disponível em: <http://ripe.ufba.br/nlpretto/videos/criancascompleto-vga.mpeg>. Acesso em: 23 fev. 2016. Ver, ainda, matéria na Rede Bandeirantes de Televisão sobre o evento, disponível em: <http://ripe.ufba.br/nlpretto/videos/criancas-faced-band>. Acesso em: 23 fev. 2016.

5 O conforto ambiental compreende as condições térmicas, acústicas, luminosas e energéticas e os fenômenos físicos a elas associados como um dos condicionantes da forma e da organização do espaço. Disponível em: <http://www.forumdaconstrucao.com.br/conteudo.php?a=4\&Cod=800>. Acesso em: 15 jun. 2015.

${ }_{6}$ Um fab lab (laboratório de fabricação, do inglês fabrication laboratory) é uma pequena oficina oferecendo fabricação digital. É, geralmente, equipado com um conjunto de ferramentas flexíveis controladas por computador, que cobrem diversas escalas de tamanho e diversos materiais diferentes, com o objetivo de fazer "quase tudo". Isso inclui produtos tecnológicos geralmente vistos como limitados apenas para produção em massa. Disponível em: <https://pt.wikipedia.org/wiki/Fab_lab>. Acesso em: 10 abr. 2015. 


\section{Referências}

ALMEIDA, C.; ROCHA, L. O. Em busca de uma aproximação entre arquitetura e educação. Porto: CEMOrOc-Feusp, 2009.

AMARAL, A. L. Os espaços e tempos de aprender e ensinar. In: LIBÂNEO, J. C.; ALVES, N. (Org.). Temas da pedagogia: diálogo entre didática e currículo. São Paulo: Cortez, 2012. p. 245263.

AVANZO, H. A arquitetura de instituições federais de ensino superior no contexto da cultura digital. 200 f. Dissertação (Mestrado em Educação) - Universidade Federal da Bahia, Faculdade de Educação, Salvador, 2015.

BRASIL. Ministério da Educação. Plano de Desenvolvimento da Educação - razões, princípio e programas. Brasília, DF: MEC, 2007. Disponível em: <http://portal.mec.gov.br/arquivos/livro/ livro.pdf>. Acesso em: 03 abr. 2016.

. Ministério da Educação. Reestruturação e Expansão das Universidades Federais. Brasília, DF: MEC, 2007. Disponível em: <http://reuni.mec.gov.br/o-que-e-o-reuni>. Acesso em: 03 abr. 2016.

. Ministério da Educação. Relatório da Comissão Constituída pela Portaria n $n^{\circ}$ 126/2012 sobre a Análise da Expansão das Universidades Federais de 2003 a 2012. Brasília, DF: MEC, 2012.

BUFFA, E.; PINTO, G. A. Arquitetura, urbanismo, educação: campus universitários brasileiros. São Carlos: EDUFSCar, 2009.

CASTELLS, M. Sociedade em rede: a era da informação; economia, sociedade e cultura. São Paulo: Paz e Terra, 1999.

CORDEIRO, S. F. N. Tecnologias digitais móveis e cotidiano escolar: espaços/tempos de aprender. 2014. 317 f. Tese (Doutorado em Educação) - Faculdade de Educação, Universidade Federal da Bahia, Salvador, 2014.

FARIA, A. B. G. Por outras referências no diálogo arquitetura e educação: na pesquisa, no ensino e na produção de espaços educativos escolares e urbanos. Em Aberto, Brasília, DF, v. 25, n. 88, p. 99-112, jul./dez. 2012.

FRAGO, A. V.; ESCOLANO, A. Currículo, espaço e subjetividade: a arquitetura como programa. Tradução de Alfredo Veiga-Neto. 2. ed. Rio de Janeiro: DP\&A, 2001.

FRANCO, M. E. D. P et al. Expansão da educação superior e arquiteturas acadêmicas: tensões e desafios. Série Estudos - Periódico do Programa de Pós-Graduação em Educação da UCDB, Campo Grande, MT, n. 30, p. 117-139, jul./dez. 2010.

GOMES, A. R. C. Panorama da Infraestrutura do Instituto Federal de Educação, Ciência e Tecnologia da Bahia. Salvador: Prodin/Ifba, 2012.

LEMOS, A. Cibercultura e modernidade: a era da conexão. Revista Eletrónica Razon y Palavra, México, n. 41, p. 1-17, out./nov. 2004. Disponível em: <http://www.razonypalabra.org.mx/anteriores/n41/alemos.html>. Acesso em: 03 abr. 2016. 
. Cibercultura: tecnologia e vida social na cultura contemporânea. Porto Alegre: Sulina, 2002.

LÉVY, P. Cibercultura. São Paulo: Editora 34, 1999.

MACEDO, R. S. Atos de currículo e autonomia pedagógica. Petrópolis, RJ: Vozes, 2013.

Currículo: campo, conceito e pesquisa. Petrópolis, RJ: Vozes, 2012.

ORNSTEIN, S. W. Arquitetura, urbanismo e psicologia ambiental: uma reflexão sobre dilemas e possibilidades da atuação integrada. Revista da USP, São Paulo, v. 16, n. 12, p. 155-165, 2005.

PRETTO, N. L.; COSTA PINTO, C. Tecnologia e novas educações. Revista Brasileira de Educação, Rio de Janeiro, n. 31, p. 19-30, abr. 2006.

PRETTO, Nelson de Luca. Redes sociais e educação: o que quer a geração alt+tab nas ruas? Liinc em Revista, v. 10, n. 1, 2014. Disponível em: http://www.moodle.ufba.br/file.php/10203/Ativismo/ pretto_mobilizacoes_movi_sociais_educacao_semiedu_ufmt_v0_4submetido.pdf. Acesso em: 15 mar. 2014.

RIBEIRO, S. L. Espaço escolar: um elemento (in)visível no currículo. Sitientibus, Feira de Santana, n. 31, p. 103-118, jul./dez. 2004. Disponível em: <http://www2.uefs.br/sitientibus/pdf/31/ espaco_escolar.pdf>. Acesso em: 18 mar. 2013.

SAVIANI, D. O plano de desenvolvimento da educação: análise do projeto do MEC. Educação $e$ Sociedade, Campinas, SP, v. 28, n. 100 - Especial, p. 1231-1255, out. 2007. Disponível em <http:// www.cedes.unicamp.br>. Acesso em: 05 jun. 2015. 